\title{
The effectiveness of cognitive behavioral group therapy in treating bipolar disorder: a randomized controlled study
}

\section{A eficácia da terapia cognitivo-comportamental para o tratamento do transtorno bipolar: um estudo controlado e randomizado}

\author{
Rafael Thomaz da Costa, ${ }^{1}$ Elie Cheniaux, ${ }^{1}$ Pedro Augusto Legnani Rosaes, ${ }^{1}$ Marcele Regine de Carvalho, ${ }^{1}$ \\ Rafael Christophe da Rocha Freire, ${ }^{1}$ Márcio Versiani, ${ }^{1}$ Bernard Pimentel Rangé, ${ }^{2}$ Antonio Egidio Nardi ${ }^{1}$ \\ ${ }^{1}$ Institute of Psychiatry, Universidade Federal do Rio de Janeiro (UFRJ), Rio de Janeiro, RJ, Brazil \\ ${ }^{2}$ Institute of Psychology, Universidade Federal do Rio de Janeiro (UFRJ), Rio de Janeiro, RJ, Brazil
}

\begin{abstract}
Objective: Recent studies suggest that, when combined with pharmacotherapy, structured psychotherapy may modify the course of bipolar disorder. However, there are few studies that have examined the effects of cognitive behavioral group therapy on the course of this disorder. The aim of the present study was to evaluate the effectiveness of 14 sessions of cognitive behavioral group therapy, combined with pharmacotherapy, on the treatment of patients with bipolar disorder, and to compare our results against those from the use of pharmacotherapy alone. Method: Forty-one patients with bipolar I and II disorder participated in the study and were randomly allocated to one of two treatment groups; thirty-seven patients remained in the study until its completion. Mood and anxiety symptoms were measured in all subjects. Statistical analysis was used to investigate if the groups differed with respect to demographic characteristics and the scores recorded in the pre- and post-treatment stages, as well as during treatment (intra/inter groups). Results: Patients showed statistically similar population characteristics. The association of cognitive behavioral group therapy and pharmacological treatment proved to be effective. Patients who had undergone cognitive behavioral group therapy presented fewer symptoms of mania, depression and anxiety, as well as fewer and shorter mood change episodes. Conclusion: Cognitive behavioral group therapy sessions substantially contributed to the improvement of depression symptoms.
\end{abstract}

Descriptors: Bipolar disorder; Cognitive therapy; Depression; Psychotherapy; Treatment outcome

\section{Resumo}

Objetivo: Estudos recentes sugerem que uma psicoterapia estruturada aplicada junto com a farmacoterapia pode alterar o curso do transtorno afetivo bipolar. Entretanto, poucos estudos investigam os resultados da terapia cognitivo-comportamental em grupo sobre este transtorno psiquiátrico. O objetivo desta pesquisa foi avaliar a eficácia de 14 sessōes de terapia cognitivo-comportamental em grupo concomitante à farmacoterapia para bipolares e comparar com a farmacoterapia sozinha. Método: Quarenta e um pacientes com transtorno bipolar I e II participaram do estudo e foram alocados aleatoriamente para um dos dois grupos; trinta e sete preencheram todas as escalas. Os sintomas de humor e ansiedade de todos os participantes foram avaliados. A análise estatística foi utilizada para investigar se os grupos diferiam com relação aos dados demográficos e entre os escores pré-, durante e pós-tratamento (intra/intergrupos). Resultados: Os participantes dos dois grupos mostraram-se similares nas características demográficas. A adição da terapia cognitivo-comportamental em grupo ao tratamento farmacológico foi efetiva. O grupo da terapia cognitivo-comportamental em grupo apresentou menos sintomas de mania, depressão e ansiedade, bem como uma redução na frequência e duração dos episódios de humor. Conclusão: As sessōes de terapia cognitivo-comportamental em grupo foram especialmente importantes na melhora dos sintomas depressivos.

Descritores: Transtorno bipolar; Terapia cognitiva; Depressão; Psicoterapia; Resultado de tratamento

\section{Introduction}

Bipolar disorder (BD) is one of the most prevalent and serious psychiatric disorders globally, affecting $1 \%$ to $3 \%$ of the world's population. ${ }^{1}$ Accordingly, it has been the object of increased attention in the past few years. ${ }^{2-4}$ Individuals suffering from BD
Correspondence

Rafael Thomaz da Costa

Institute of Psychiatry - Federal University of Rio de Janeiro

INCT - Translational Medicine (CNPq)

R. Piauí, 413 / 203 - Todos os Santos

Rio de Janeiro, RJ, Brasil

Phone: (+55 21) 3649-6965 / (+55 21) 9509-4461

Laboratório de Pânico e Respiração - Tel.: (+55 21) 2521-6147 Fax:

(+55 21) 2523-6839

Email: faelthomaz@ig.com.br 
often experience impairments in both their personal, (marital, family) and professional lives. ${ }^{1}$

Even when the genetic, biological and psychopharmacological aspects involved in the treatment of symptoms of $\mathrm{BD}$ are considered, about $40 \%$ of bipolar patients do not respond well to lithium or other mood stabilizers. ${ }^{5-7}$ In spite of receiving the required medication dose, these patients remain free of relapses for a maximum of only two- to three-year follow-up periods. ${ }^{5,8}$ Moreover, growing evidence suggests that structured psychotherapy used in combination with pharmacotherapy may modify the course of BD. ${ }^{4,9}$

Until a few years ago, it was widely believed that psychosocial approaches only served the purpose of improving pharmacologic adherence given that $\mathrm{BD}$ has a strong biological component. Nonetheless, the efficacy of psychotherapy in the treatment of this disorder is considerable. ${ }^{3}$ More recently, it has been demonstrated that psychosocial approaches also improve patients' quality of life, and that better results can be attained in the treatment of depression compared to that of mania. ${ }^{10}$

Cognitive behavioral therapy (CBT) used in conjunction with pharmacotherapy in $\mathrm{BD}$ patients can modify the course of the disease. Certain studies on the association between individual or group CBT and BD have reported improvements in mood and social functioning. Upon further investigation, it was discovered that such improvements were maintained at follow-up. ${ }^{11-13}$ However, a recent study concluded that CBT is not likely to be an effective adjunctive therapy for the general population with recurrent non-rapid cycling $\mathrm{BD},{ }^{13}$ while other studies emphasize that CBT generated better results in the treatment of depression when compared to that of mania. ${ }^{14-17}$

CBT strategies aim at managing and preventing cognitive, affective and behavioral symptoms associated with depressive or manic phases, and are conducted with the patient, as well as, sometimes, with his or her family's active cooperation. ${ }^{18}$ Such strategies intend to reduce the negative impacts of $\mathrm{BD}$ in the psychosocial and interpersonal domains, thus improving the quality of life of individuals with BD. ${ }^{19}$

CBT interventions for $\mathrm{BD}$ are intended to achieve the following: (1) educate the patient and his/her family about the treatment, as well as about the common difficulties associated with the disease; (2) teach them how to monitor manic or depressive symptoms using, for example, a mood chart, and to assess their severity; (3) promote compliance with pharmacological treatment (i.e., psycho-education and reality test of thoughts and beliefs; (4) provide subjects with psychological strategies, especially in terms of cognitive-behavioral skills, that will allow them to manage stress factors which, in turn, can interfere with treatment or bring on manic and/or depressive episodes (e.g., circadian rhythm control, daily thought records, social skills training, problem solving); and (5) reduce the trauma and stigma associated with the diagnosis. ${ }^{19,20}$

The objective of this study is to evaluate the effectiveness of CBGT in $\mathrm{BD}$ cases. We tried to assess the effectiveness of 14 sessions of CBGT as a combined intervention used to control mood symptoms.
The study was approved by the Research Ethics Committee (Brazilian National Research Ethics Committee - protocol no. 07/06).

\section{Method}

\section{Inclusion and exclusion criteria}

Subjects were recruited from the Institute of Psychiatry of the Universidade Federal do Rio de Janeiro (Anxiety and Depression Program Outpatient Clinic). Their age ranged between 18 and 60 years, they met the DSM-IV criteria for BD I or II, and had experienced at least one hypomanic, manic or depressive episode in the previous 12 months. Subjects had been taking moodstabilizing medication for a minimum of one month before the therapy was initiated.

Patients were eligible for inclusion if they were euthymic, mildly depressed or mildly hypomanic at the time of the initial assessment. They were excluded if they had a Beck Depression Inventory score $\geq 35(\mathrm{BDI})^{21}$ and a Young Mania Rating Scale score $\geq 20$ (YMS) ${ }^{22}$ or presented a comorbid personality disorder and/or any other axis I severe psychiatric disorder. This was established using the Structured Clinical Interview for DSMIV-TR (SCID- I and II). ${ }^{23}$ Patients suffering from any severe physical illness and/or using alcohol or illicit drugs were referred to individual psychotherapy.

Patients who required the administration of a new mood stabilizer and/or a new antidepressant during the course of treatment were also excluded from the study.

\section{Subjects}

Forty-one subjects with BD I ( $\cong 84 \%$ in each group) or II participated in the study. The number of subjects from each therapy group varied from 5 to 6 . Only two subjects from each group did not answer any of the instruments of the scales. Two subjects from the control group and one from the CBGT group required hospitalization, and one from the CBGT group walked away because he preferred to go on individual therapy.

\section{Instruments}

Subjects were interviewed using the Structured Clinical Interview for DSM-IV (SCID- I and II). ${ }^{23}$

Mood and anxiety symptoms were assessed in all subjects using the Beck Depression Inventory (BDI), ${ }^{21}$ the Young Mania Rating Scale (YMRS) ${ }^{22}$ and the Beck Anxiety Inventory (BAI). ${ }^{24}$ The Beck Hopelessness Scale (BHS) ${ }^{25}$ was used for predicting suicidal ideation.

Weekly scores on the BDI and BAI were obtained for both groups. The YMRS was applied at three different moments in time i.e., at the beginning, the middle and at the end of treatment, whereas the BHS was applied only at the beginning and at the end of the study period.

\section{Treatment procedures}

Patients were randomly allocated to CBGT $(\mathrm{n}=27)$ and to treatment as usual (TAU, $\mathrm{n}=14$ ). They were assessed before, 
during and after treatment, and up to 6 months post-treatment in terms of their levels of depression, mania and their quality of life scores.

1) Treatment as usual (TAU)

The TAU group attended sessions as prescribed by their respective psychiatrists, and did not attend any psychotherapy session. Doctors who had been trained on how to apply the tests assessed mood symptoms throughout the 14 weeks and at the 6-month follow up session.

\section{2) CBGT}

The protocol was administered by an experienced clinical psychologist. It consisted of 14 two-hour CBGT sessions which were divided into two stages: the first consisted of three sessions during which the therapist provided psychoeducation on $\mathrm{BD}$, symptoms and medications to the patients and their families. In the second stage, patients learned CBT skills by means of specific behavioral and cognitive interventions. The CBGT protocol used in the present study was based on the treatment manual 'Cognitive Behavioral Therapy for Bipolar Disorder' by Basco and Rush. ${ }^{18}$

\section{Statistical analysis}

Pearson chi-square tests and ANOVA were performed to investigate if the control group and the CBGT group differed with respect to demographic characteristics and comorbid diagnoses. Paired-sample t-test and regression were used to test for differences among scores recorded at the pre-, during- and post-treatment stages, both within the same group and between groups. ANOVA was used to compare mean differences found in both groups at two moments in time i.e., pre and post-treatment, and a multiple regression analysis was performed so that we could understand how the value of the dependent variable changed when any of the independent variables changed while the other independent variables remained the same. The significance level was set at $\mathrm{p}<0.05$.

\section{Results}

Statistically speaking, patients shared similar population characteristics as seen in the demographic information presented in Table 1.

The groups did not present any significant difference in terms of their baseline scores on the BDI, BAI and YMRS scales. Table 2 shows the correlations between the clinical scores and the two groups before the first session. The clinical scores were categorized as subclinical, mild, moderate and severe depression/anxiety, and as subclinical, hypomania and mania.

On one hand, it is important to note that the average depression scores indicated the presence of mild depression in both groups. On the other hand, the scores on the YMRS pointed towards the presence of sub-clinical hypomanic/manic symptoms in the two groups. With respect to anxiety, subjects from the CBGT group presented average mild anxiety, whereas subjects from the TAU group presented sub-clinical anxiety. However, the number of patients with subclinical, mild, moderate or severe anxiety was not statistically different between the groups.
Table 1 - Demographic characteristics of subjects - statistically independent of group $(n=37)$

\begin{tabular}{lcc}
\hline & $\%$ & $\mathbf{p}$ \\
\hline Sex & & \\
Women & 67.6 & 0.935 \\
Mean age (years \pm SD) & $40.5 \pm 10.7$ & 0.704 \\
Marital status & & 0.706 \\
Single & 37.8 & \\
Married & 29.7 & \\
Divorced / Separated & 32.4 & \\
Level of education & & 0.661 \\
Primary school & 8.2 & \\
Incomplete high school or high & & \\
school & 45.9 & \\
Incomplete university education or & & \\
University education & 45.9 & \\
Psychiatric comorbidity & & 0.271 \\
Axis I & 29.7 & \\
No psychiatric comorbidity & 70.3 & \\
\hline
\end{tabular}

The scores of both groups at the beginning, middle and at the end of the treatment are shown in Table 3.

The graphs below indicate the variations in the anxiety and depression scores over a period of 14 weeks.

By initially examining the within-group results, one can say that there were no significant differences in the depression (BDI; $\mathrm{p}=0.210)$ and anxiety scores (BAI; $\mathrm{p}=0.234$ ) among control group subjects over the fourteen weeks. The same was true for this group's scores on manic symptoms (YMRS; $\mathrm{p}=0.243$ ) and hopelessness (BHS; $\mathrm{p}=0.312$ ). However, in the CBGT group, there was a significant difference over time in the depression (BDI; $\mathrm{p}=0.000)$ and anxiety (BAI; $\mathrm{p}=0.000)$ scores, which means that, in the course of those 14 weeks, scores fell. A significant fall was seen over the 14 weeks in the manic symptoms index scores (YMRS; $\mathrm{p}=0.000)$ and between the initial and final scores on hopelessness (BHS; $\mathrm{p}=0.000$ ).

Regression analyses also showed favorable results for the CBGT group. Of all the variables included in the study, the only one that appeared to be significantly associated with reduced depression scores was the treatment group, thus favoring CBGT ( $\mathrm{R}$ square $=0.909 / \mathrm{p}=0.002)$. Time point during the course of the study significantly predicted a change in anxiety scores for

Table 2 - Baseline scores

\begin{tabular}{lcccc}
\hline & BDI-1 & BAl-1 & YMRS-1 & BHS-1 \\
\cline { 2 - 5 } & Mean (SD) & Mean (SD) & Mean (SD) & Mean (SD) \\
\hline Control & 11.67 & 8.00 & 1.33 & 4.42 \\
group & $(8.392)$ & $(4.178)$ & $(3.367)$ & $(3.630)$ \\
CBGT & 19.52 & 18.6 & 9.68 & 7.04 \\
& $(9.794)$ & $(14.101)$ & $(8.025)$ & $(4.523)$ \\
Total & 16.97 & 15.16 & 6.97 & 6.19 \\
& $(9.968)$ & $(12.775)$ & $(7.879)$ & $(4.383)$ \\
ANOVA - & 0.083 & 0.096 & 0.102 & 0.088 \\
sig & & & & \\
\hline
\end{tabular}


Table 3 - Comparing group scores

\begin{tabular}{|c|c|c|c|c|c|c|c|c|}
\hline \multirow[b]{3}{*}{ Wenk } & \multicolumn{4}{|c|}{ Control group $(n=12)$} & \multicolumn{4}{|c|}{ CBGT $(n=27)$} \\
\hline & $\mathrm{BDI}$ & BAI & YMRS & BHS & $\mathrm{BDI}$ & BAI & YMRS & BHS \\
\hline & Mean (SD) & Mean (SD) & Mean (SD) & Mean (SD) & Msan (SD) & Mean (SD) & Mean (SD) & Mean (SD) \\
\hline Brseline & $11.67(8.39)$ & $8.00(4.178)$ & $1.33(3.37)$ & $4.42(3.63)$ & $19.52(9.79)$ & $18.60(14.10)$ & $9.68(8.03)$ & $7.04\langle 4.52\rangle$ \\
\hline 7 & $12.58(8.36)$ & $5.92(5.017)$ & $3.17(3.16)$ & & $12.00(7.90)$ & $12.48(12.19)$ & $6.72(8.20)$ & \\
\hline \multirow[t]{3}{*}{14} & $13.92(9.17)$ & $6.17(5.254)$ & $2.92(2.81)$ & $5.25(4.35)$ & $7.24(6.42)^{*}$ & $7.16(7.97)^{*}$ & $2.24(3.22)^{*}$ & $3.60(4.08)^{\circ}$ \\
\hline & \multicolumn{4}{|c|}{ Control group $(n=12)$} & \multicolumn{4}{|c|}{$\operatorname{CBGT}(n=27)$} \\
\hline & $\mathrm{BDI}$ & BAI & YMRS & BHS & $\mathrm{BDI}$ & BAI & YMRS & BHS \\
\hline Week & Mean (SD) & Mean (SD) & Mean (SD) & Mean (SD) & Mean (SD) & Mean (SD) & Mean (SD) & Mean (SD) \\
\hline B-7 & 0.544 & 0.033 & 0.130 & & 0.001 & 0.014 & 0.039 & \\
\hline $7-14$ & 0.480 & D. 867 & 0.714 & & 0.003 & 0.011 & 0.000 & \\
\hline B-14 & 0.210 & 0.234 & 0.243 & 0.312 & 0.000 & 0.000 & 0.000 & 0.000 \\
\hline
\end{tabular}

* Significant differences between the baseline and fourteceth woek: $p<0,01$

the CBGT group. Specifically, the eleventh session represented a key moment in terms of reduced anxiety $(\mathrm{R}$ square $=0.904 \mathrm{I}$ $\mathrm{p}=0.027)$. Mania scores were not particularly associated with any variable $(\mathrm{R}$ square $=0.355 / \mathrm{p}=0.151)$; this indicates that the model did not function well. Finally, the BHS, which regression analysis indicated as being part of the CBGT, was associated with reduced hopelessness $(\mathrm{R}$ square $=0.551 / 0.002)$. However, using the same scale, the higher the BHS score recorded in the first week, the higher this same score was recorded in the last treatment week ( $\mathrm{R}$ square $=0.355 / 0.000)$.

\section{Discussion}

Unfortunately, to this date, only a few studies have investigated the efficacy of CBGT in BD patients. One such study compared results before and after CBT plus pharmacotherapy, ${ }^{11}$ and another study compared CBT plus pharmacotherapy versus pharmacotherapy alone. ${ }^{12}$ Neither study included a control group.

Palmer et al. evaluated the effectiveness of 17 weekly sessions of CBGT in six bipolar patients who were on maintenance mood stabilizers. ${ }^{11}$ Results showed that two patients experienced a significant improvement and that a third one showed a trend towards improved well-being. All patients showed improvements

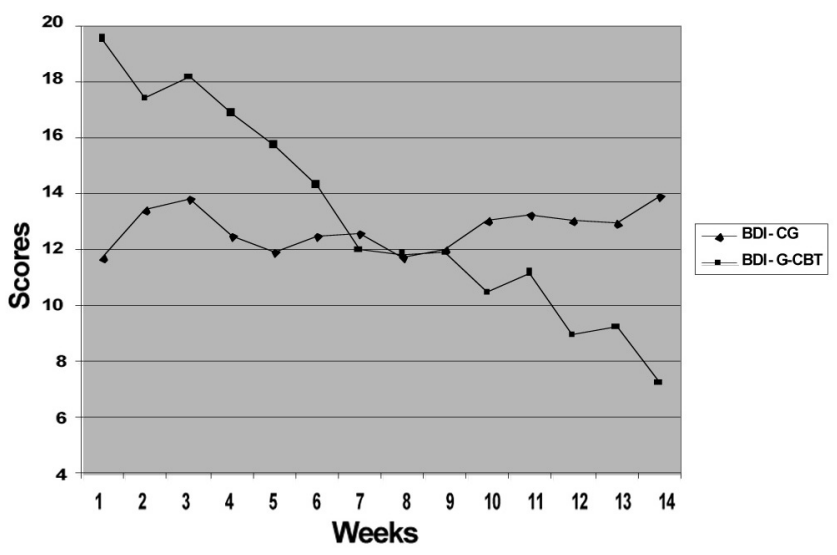

Figure 1 - BDI scores in social adjustment in pre- to post-test. ${ }^{11}$ In another study, Patelis et al. showed that the inclusion of 14 sessions of CBGT to promote pharmacotherapy adherence had improved the functioning and quality of life of 38 bipolar patients. By the end of the treatment, scores had changed significantly in favour of the CBGT group. ${ }^{12}$ The group protocol derived from a combination of sources, including Basco and Rush ${ }^{18}$ and Newman. ${ }^{26}$

In spite of the number of treatment sessions mentioned above, we are unable to compare results since subjective measures and follow-up varied widely between studies. Considering that the authors have acknowledged some of the limitations of their respective studies, our ability to interpret their results is rather limited. These limitations, which include the absence of a control group against which to compare the results from the experimental group and possible individual changes in medication that may account for the improvements seen in patients, can however be overcome in future studies.

Group therapy was well tolerated by all subjects, as evidenced by the fact that $92.59 \%$ of them remained in the program from beginning to end, thus corroborating the findings of Patelis-Siotis et al. ${ }^{12}$

The inclusion of CBGT as part of the pharmacological treatment was effective. After treatment, participants presented fewer manic,

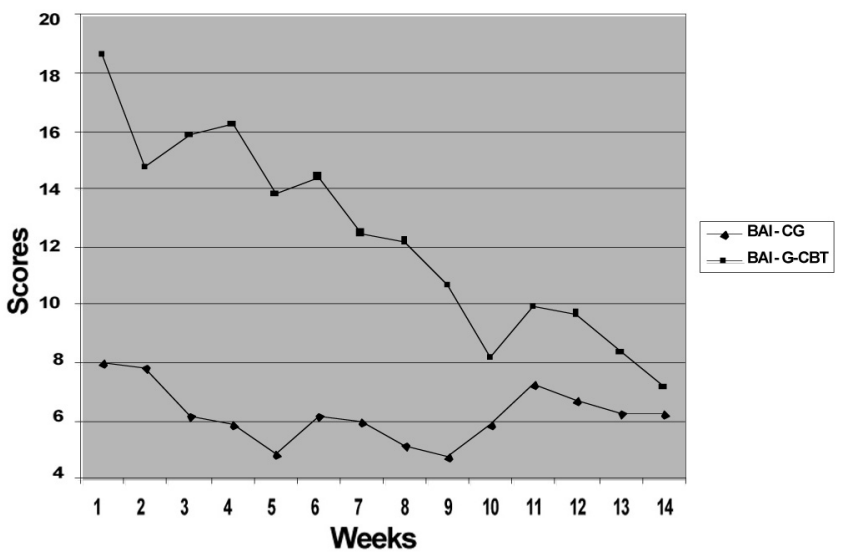

Figure 2 - BAI scores 
depressive and anxiety symptoms and a reduction in the frequency and duration of mood change episodes.

CBGT sessions were essential for the improvement of depressive symptoms, which supports the findings of Scott et al., ${ }^{27}$ Ball et al., ${ }^{28}$ and Reilly-Harrington et al., ${ }^{29}$ who investigated the efficacy of individual CBT.

Although the mania index scores did fall, in regression, the model did not prove to be functional. It is particularly important to note that subjects from both groups had low YMRS scores in the first assessment (i.e., pre-treatment) and were all medicated with mood stabilizers. This explains why we were less likely to see lower scores.

A limitation of this study is the exclusion of patients with severe mania or severe depression. Although there were no significant differences in baseline scores, subjects from the CBGT group had slightly higher mean raw anxiety, depression and mania scores after treatment compared to before treatment. This could lead to a less apparent reduction in symptoms in subjects from the control group. Furthermore, we did not conduct a reassessment to evaluate whether the patients had sustained the gains made during therapy. Another limitation of this study is its small sample size, especially that of the control group $(n=12)$. Nevertheless, we see the presence of a control group as a strength.

\section{Conclusion}

The inclusion of CBGT as part of the pharmacological treatment was effective. Patients receiving CBGT presented fewer symptoms of mania, depression and anxiety. Subjects from the
CBGT group also experienced fewer and shorter mood change episodes. CBGT sessions were especially important for the improvement of depression symptoms.

\section{Acknowledgements}

This study was conducted at the Panic and Respiration Laboratory and at the INCT Translational Medicine, Institute of Psychiatry, Universidade Federal do Rio de Janeiro (IPUB-UFRJ), Rio de Janeiro, RJ, Brazil. This study received a grant from the Brazilian Council for Scientific and Technological Development (CNPq).

Disclosures

\begin{tabular}{|c|c|c|c|c|c|c|c|}
\hline $\begin{array}{l}\text { Writing group } \\
\text { member }\end{array}$ & Employment & $\begin{array}{l}\text { Research } \\
\text { grant }^{1}\end{array}$ & $\begin{array}{c}\text { Other research grant or } \\
\text { medical continuous } \\
\text { education }^{2}\end{array}$ & $\begin{array}{l}\text { Speaker's } \\
\text { honoraria }\end{array}$ & $\begin{array}{c}\text { Ownership } \\
\text { interest }\end{array}$ & $\begin{array}{l}\text { Consultant/ } \\
\text { Advisory } \\
\text { board }\end{array}$ & Other ${ }^{3}$ \\
\hline $\begin{array}{l}\text { Rafael Thomaz } \\
\text { da Costa }\end{array}$ & IPUB/UFRJ & $\mathrm{CNPq}$ & - & - & - & - & - \\
\hline Elie Cheniaux & IPUB/UFRJ & - & - & - & - & - & - \\
\hline $\begin{array}{l}\text { Pedro Augusto } \\
\text { Legnani Rosaes }\end{array}$ & IPUB/UFRJ & - & - & - & - & - & - \\
\hline $\begin{array}{l}\text { Marcele Regine } \\
\text { de Carvalho }\end{array}$ & IPUB/UFRJ & $\mathrm{CNPq}$ & - & - & - & - & - \\
\hline $\begin{array}{l}\text { Rafael } \\
\text { Christophe da } \\
\text { Rocha Freire } \\
\end{array}$ & IPUB/UFRJ & $\mathrm{CNPq}$ & - & - & - & - & - \\
\hline Márcio Versiani & IPUB/UFRJ & - & - & - & - & - & - \\
\hline $\begin{array}{l}\text { Bernard Pimentel } \\
\text { Rangé }\end{array}$ & $\begin{array}{c}\text { Instituto de } \\
\text { Psicologia/UFRJ }\end{array}$ & - & - & - & - & - & - \\
\hline $\begin{array}{l}\text { Antonio Egidio } \\
\text { Nardi }\end{array}$ & IPUB/UFRJ & - & - & - & - & - & - \\
\hline \multicolumn{8}{|c|}{$\begin{array}{l}{ }^{*} \text { Modest } \\
{ }_{* \star *}^{*} \text { Significant } \\
\text { author. } \\
\text { Note: IPUB/UFRJ = Instituto de Psiquiatria, Universidade Federal do Rio de Janeiro; UFRJ = Universidade Federal do Rio de Janeiro; CNPq = } \\
\text { Conselho Nacional de Desenvolvimento Científico e Tecnológico. } \\
\text { For more information, see Instructions for Authors. }\end{array}$} \\
\hline
\end{tabular}




\section{References}

1. Judd LL, Akiskal HS. The prevalence and disability of bipolar spectrum disorders in the USA population: re-analysis of the ECA atabase taking into account subthreshold cases. J Affect Disord. 2003;73(1-2):123-31.

2. Jones S. Psychotherapy of bipolar disorder: a review. J Affect Disord. 2004;80(23):101-14.

3. Miklowitz DJ, Otto MW, Frank E, Reilly-Harrington NA, Wisniewski SR, Kogan JN. Psychosocial treatments for bipolar depression: a 1-year randomized trial from the Systematic Treatment Enhancement Program. Arch Gen Psychiatry. 2007;64(4):419-42.

4. Miklowitz DJ. Adjunctive psychotherapy for bipolar disorder: state of the evidence. Am J Psychiatry. 2008;165(11):1408-19.

5. Keck PE, McElroy S. Outcome in the pharmacologic treatment of bipolar disorder. J Clin Psychopharmacol. 1996;16(1):15-23.

6. Swann AC, Bowden CL, Morris D, Calabrese JR, Petty F, Small J, Dilsaver SC, Davis JM.Depression during mania. Treatment response to lithium or divalproex. Arch Gen Psychiatry. 1997;54(1):37-42.

7. Bowden CL, Calabrese JR, Sachs G, Yatham LN, Asghar SA, Hompland M, Montgomery P, Earl N, Smoot TM, DeVeaugh-Geiss J; Lamictal 606 Study Group.A placebo-controlled 18-month trial of lamotrigine and lithium maintenance treatment in recently manic or hypomanic patients with bipolar I disorder. Arch Gen Psychiatry. 2003;60(4):392-400.

8. Solomon DA, Keitner GI, Miller IW, Shea MT, Keller MB. Course of illness and maintenance treatments for patients with bipolar disorder. J Clin Psychiatry. 1995;56(1):5-13.

9. Vieta E, Pacchiarotti I, Scott J, Sánchez-Moreno J, Di Marzo S, Colom F. Evidence-based research on the efficacy of psychological interventions in bipolar disorders: a critical review. Curr Psychiatry Rep. 2005;7(6):449-55.

10. Sachs GS. Unmet clinical needs in bipolar disorder. J Clin Psychopharmacol. 2003;3(1):2-8.

11. Palmer AG, Williams H, Gorsefield D, Adams M. CBT in a group format for bipolar affective disorder. Behav Cogn Psychother. 1995;23:153-68.

12. Patelis-Siotis I, Young LT, Robb JC. Group cognitive behavioral therapy for bipolar disorder: a feasibility and effectiveness study. J Affect Disord. 2001;65(2):145-53.

13. Scott J, Colom F, Vieta E. A meta-analysis of relapse rates with adjunctive psychological therapies compared to usual psychiatric treatment for bipolar disorders. Int J Neuropsychopharmachol. 2006;10(1):123-9.

14. Miklowitz DJ, Johnson SL. On the role of goal dysregulation in the treatment of bipolar disorder. Clin Psychol. 2009;16(4):470-75.

15. Zaretsky A, Lancee W, Miller C, Harris A, Parikh SV. Is cognitive-behavioral therapy more effective than psychoeducation in bipolar disorder? Can J Psychiatry. 2008;53(7):441-8.

16. Parikh S, Zaretsky A, Beaulieu S. Psycho-education versus cognitive behavioral therapy for bipolar disorder: A multi-site national RCT. Paper presented at the Annual Meeting of the American Psychiatric Association. Washington, DC: American Psychiatric Association; 2007.

17. Lam DH, Hayward P, Watkins ER, Wright K, Sham P. Relapse prevention in patients with bipolar disorder: cognitive therapy outcome after 2 years. Am J Psychiatry. 2005;162(2):324-9.

18. Basco MR, Rush AJ. Cognitive-behavioral therapy for bipolar disorder. New York: Guilford Press; 1996.

19. Lam DH, Jones SH, Hayward P, Bright JA. Cognitive Therapy for Bipolar Disorder: A Therapist's Guide to Concepts, Methods and Practice. New York, NY: John Wiley and Sons; 1999.

20. Newman C. Bipolar disorder: a cognitive therapy approach. Washington, DC: American Psychological Association; 2002.

21. Beck AT, Ward CH, Mendelson M, Erbaugh J. An inventory for measuring depression. Arch Gen Psychiatry. 1961;4:561-71.

22. Young RC, Biggs JT, Ziegler VE. A rating scale for mania: reliability, validity and sensitivity. Br J Psychiatry. 1978;133:429-35.

23. First MB, Gibbon M, Spitzer RL, Williams JBW. User guide for the structured clinical interview for DSM-IV Axis 1 disorders. Washington, DC: American Psychiatric Association; 1996.
24. Beck AT, Epstein N, Brown G, Steer RA. An inventory for measuring clinical anxiety: psychometric properties. J Consult Clin Psychol. 1988;56(6):893-7.

25. Beck AT, Kouacs M, Weissman A. Hopelessness and suicidal behaviour. J Am Med Assoc. 1975;234:1146-9.

26. Otto MW, Miklovitz DJ. The Role and Impact of Psychotherapy in the Management of Bipolar Disorder. CNS Spectrums. 2004;9(11):27-32.

27. Scott J, Garland A, Morhead S. A pilot study of cognitive therapy in bipolar disorders. Psychol Med. 2001;31(3):459-67.

28. Ball JR, Mitchell PB, Corry JC, Skillecorn A, Smith M, Malhi GS. A randomized controlled trial of cognitive therapy for bipolar disorder: focus on long-term change. J Clin Psychiatry. 2006;67(2):277-86.

29. Reilly-Harrington NA, Deckersbach T, Knauz R, Wu Y, Tran T, Eidelman P, Lund HG, Sachs G, Nierenberg AA.Cognitive behavioral therapy for rapid-cycling bipolar disorder: a pilot study. J Psychiatr Pract. 2007;13(5):291-7. 